\title{
(2) OPEN ACCESS \\ Extranodal NK/T cell lymphoma, nasal type: a rare diagnosis with common nasal presentation
}

\author{
Siti Sarah Mohd Ramli ๑, ' Salina Husain $\odot$,' Yin Ping Wong $\odot^{2}$
}

\begin{abstract}
${ }^{1}$ Otorhinolaryngology, Pusat Perubatan Universiti Kebangsaan Malaysia, Cheras, Kuala Lumpur, Malaysia ${ }^{2}$ Pathology, Pusat Perubatan Universiti Kebangsaan Malaysia, Cheras, Kuala Lumpur, Malaysia
\end{abstract}

Correspondence to

Dr Salina Husain;

drsalina_h@yahoo.com

SH and SSMR are joint first authors.

Accepted 1 June 2021

Check for updates

(c) BMJ Publishing Group Limited 2021. Re-use permitted under CC BY-NC. No commercial re-use. See rights and permissions. Published by BMJ.

To cite: Mohd Ramli SS, Husain S, Wong YP. BMJ

Case Rep 2021;14:e236436. doi:10.1136/bcr-2020-

236436

\section{SUMMARY}

A 39-year-old man presented with bilateral nasal obstruction for 4 months and associated with hyposmia and foul-smelling nasal discharge. Nasal endoscopy showed irregular mucosa of the nasal cavity with easily bleeding. Nasal biopsy reported as extranodal Natural Killer/T cell lymphoma, nasal type. In-situ hybridisation for Epstein-Barr encoding region was positive. He was treated with six cycles of gemcitabine, oxaliplatin and L-asparaginase and peripheral blood stem cell transplant. After the treatment, he was asymptomatic until 9 months where he had splenic abscess and undergone splenectomy. He was asymptomatic of the disease for 2 years.

\section{BACKGROUND}

Extranodal Natural Killer/T cell lymphoma, nasal type (ENKTCL,NT) nasal type is an aggressive, rare subtype of non-Hodgkin's lymphoma (NHL) which $70 \%-80 \%$ of ENKTCL,NT occurs at upper aerodigestive tract. ${ }^{1-3}$ It constitutes of only $3 \%-12 \%$ cases of NHL. ${ }^{4-7}$ The prevalence of ENKTCL,NT is higher in Asia, where 8\% in Hong Kong, as compared with the Western countries where it only accounts for $2 \%$ of NHL in Lyon. ${ }^{7-9}$ All of ENKTCL,NT was accompanied with infection of Epstein-Barr virus (EBV) ${ }^{10} 11$ and EBV DNA load is a surrogate marker for patient's prognosis. ${ }^{12}$

\section{CASE PRESENTATION}

A previously healthy 39-year-old man presented with progressive bilateral nasal obstruction for 4 months. It was associated with foul smelling discharge, epistaxis and hyposmia. He was an active smoker but there was no history of malignancy in his family. In clinical setting, both nasal cavity were obstructed with oedematous nasal mucosa. There was no cervical node palpable. Nasal endoscopy under anaesthesia revealed irregular, oedematous and easily bled septal mucosa obstructing the nasal passage bilaterally (figure 1). There was no mass or pus discharge seen at the osteomeatal complex.

\section{INVESTIGATIONS}

Full blood picture showed leucoerythroblastic picture with occasional myelocytes and nucleated red blood cells(NRBC). There was severe normochromic, normocytic anaemia. Otherwise, the red cells showed no abnormalities and white blood cells were within normal range. There was no abnormal lymphoid cells seen.

Serum renal profile and liver function test showed normal findings.
Computed tomography scan (CT scan) of the paranasal sinuses revealed an enhancing soft tissue density lesion occupying right nasal cavity with deviation of nasal septum to the left (figure 2). There were remodelling and thinning of adjacent bones. Ethmoid sinuses, sphenoethmoidal and frontoethmoidal recesses were obliterated. There was no significant neck node seen.

Histopathological examination of the lesion (figure 3) exhibited diffuse sheets of malignant lymphoid cells in a mixed inflammatory background. The malignant lymphoid cells displayed enlarged, pleomorphic hyperchromatic nuclei with inconspicuous nucleoli and moderate cytoplasm. Frequent mitosis was observed. Angio-centricity and angiodestruction were focally noted, leading to zonal necrosis.

Immunohistochemical studies (figure 4) reported the malignant lymphoid cells were positive for CD3, CD2, CD5, CD7, CD8 and TIA-1. The proliferation index (Ki 67) was about 30\%. Epstein-Barr encoding region (EBER) was tested positive by in situ hybridisation confirming the diagnosis of ENKTCL,NT.

Bone marrow biopsy showed tumour cells infiltration forming focal aggregates at central area. The tumour cells were moderate to large in size, irregular nuclear outline, vesicular chromatin with prominent nucleoli and abundant cytoplasm. Immunohistochemical staining showed the abnormal lymphoid cells were positive to CD2, CD3, CD5, CD7, TIA-1 and in situ hybridisation for EBER. It was negative for CD20 and CD56. This was consistent with infiltration by NK/T cell lymphoma.

Positron emission tomography-computed tomography (PET-CT) was done prior to treatment for staging of ENKTCL, NT and disease was only presented at paranasal sinuses, nasopharynx and oropharynx.

\section{DIFFERENTIAL DIAGNOSIS}

Due to the history and examination during the first encounter, the provisional diagnosis was bilateral nasal polyposis with consideration of inverted papilloma.

Post examination of the nose under anaesthesia, the diagnosis was sinonasal granulomatous disease with query of Wegener granulomatosis. ENKTCL, NT was lower on the list. Histopathological examination confirmed of the diagnosis of ENKTCL, NT, stage IV disease based on Ann Arbor staging system as there was bone marrow filtration.

\section{TREATMENT}

He was treated with six cycles of a combination of gemcitabine, oxaliplatin and L-asparaginase 


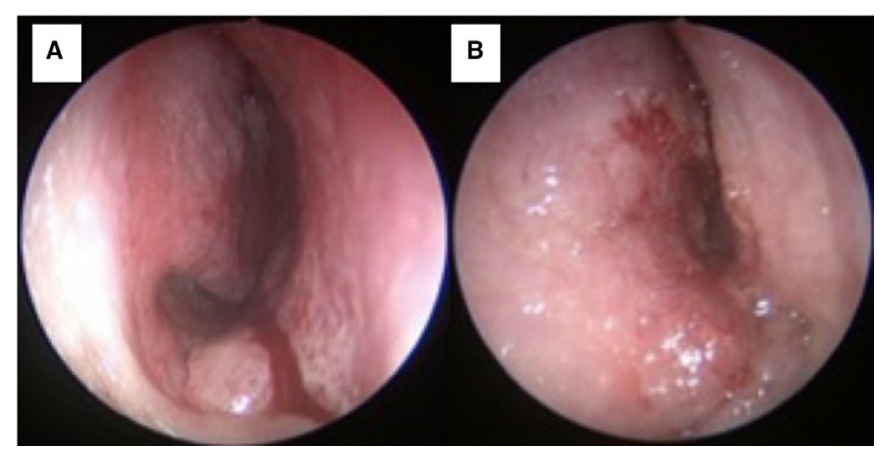

Figure 1 Endoscopic findings. (A) (right nasal cavity) and (B) (left nasal cavity) showed oedematous and irregular nasal mucosa.

(GELOX) with additional intravenous gemcitabine. Peripheral blood stem cell transplantation (PBSCT) showed complete engraftment within 3 weeks.

\section{OUTCOME AND FOLLOW-UP}

PET-CT study 6 months post-PBSCT showed complete metabolic response. There was no active disease at primary site (nasal cavities). However, he developed prolonged fever and lethargy with pancytopenia 9 months post treatment. Blood culture and sensitivity showed no growth. Cytogenetic analysis of the G-banded chromosomes from cultured bone marrow showed a male chromosome complement with no evidence of a clonal abnormality. CT scan showed hepatosplenomegaly with multiple hypodensities consistent with splenic abscess. He underwent splenectomy. At 18 months follow-up, the patient was asymptomatic of nasal symptoms and nasal endoscopy revealed normal nasal and septal mucosa.

\section{DISCUSSION}

WHO recognises three major categories of extranodal ENKTCL; ENKTCL, NT, which started with nasal symptoms; enteropathytype, which patient presented with coeliac disease; and subcutaneous panniculitis like, which patient presented with multiple subcutaneous nodules. ${ }^{13} 14$ ENKTCL,NT is an aggressive type of NHL that accounted around 3\%-12\% of all cases of NHL, ranging highest in Asian and lower percentage of all NHL in Western countries. ${ }^{14}$ In Malaysia, the difference of disease prevalence between ethnicity was observed, where Chinese was found to be more predisposed to EBV-associated tumour such as ENKTCL,NT compared with non-Chinese group which was half of the risk. ${ }^{11}$ It affects male patients more than female. ${ }^{15}$

Initially, majority of ENKTCL, NT patients presented with general nasal symptoms such as nasal obstruction, epistaxis, nasal discharge and reduced smell sensation, which might be mistaken

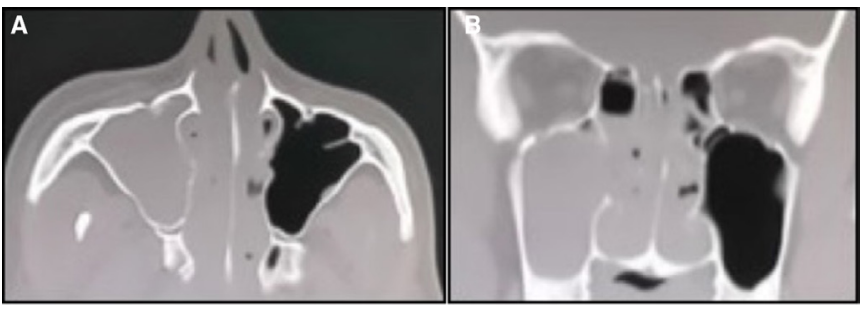

Figure 2 CT scan of paranasal sinus. (A) (Axial view) and (B) (coronal view) showed enhancing soft tissue density lesion in nasal cavities with obliteration of right maxillary and ethmoid sinuses. There was thinning and remodelling of adjacent bones and septal deviation to the left.

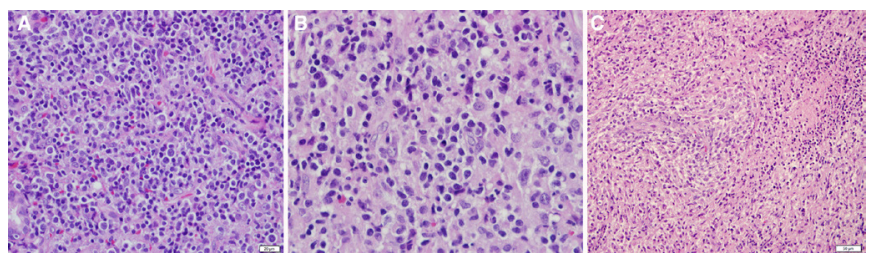

Figure 3 Histopathological examination. (A) There was diffuse infiltration by malignant lymphoid cells in a mixed inflammatory background comprised of small lymphocytes, plasma cells and eosinophils (H\&E x400). (B) The malignant lymphoid cells displayed enlarged, irregular pleomorphic vesicular nuclei with small nucleoli (H\&E x600). (C) Angiocentricity and angiodestruction, leading to zonal necrosis (H\&E x400).

for bacterial or fungal rhinosinusitis or in more progressive disease, patients might be suspected for more common condition such as Wegener granulomatosis, ${ }^{15} 16$ inverted papilloma, and in some region, nasal tuberculosis. As the disease progressed, most patient presented with facial oedema, mid face necrosis and destruction of adjacent structures occur, which caused collapsed of the lateral nasal wall cavity and oronasal fistula. ${ }^{15} 16$

In locally advanced cases, there would be involvement of orbits, hard palate, oropharynx and larynx. ${ }^{17}$ Multiple biopsies may be required as there would be abundant of necrotic tissues. ${ }^{15}$ Delay of diagnosis may lead to dissemination of disease to lungs, gastrointestinal tract, testicles, kidneys, pancreas, central nervous system and skin. ${ }^{16}{ }^{17}$ ENKTCL,NT might spread to marrow and presented with leukaemic phase. ${ }^{17}$ Our patient had bone marrow infiltration with severe normochromic normocytic anaemia without pancytopenia.

Studies in Asia found that ENKTCL,NT patients was positive for in situ hybridisation of EEBER. ${ }^{11}{ }^{17}$ The presence of EBV was deemed to be required for diagnosis of ENKTCL,NT. ${ }^{2}$ Studies showed EBV has two subtypes; A and B, where subtype A was found common in many Asian ENKTCL,NT cases ${ }^{18}$ and might be an important etiopathogenetic component for Asian with ENKTCL,NT. ${ }^{11}$ High circulation EBV-DNA pretreatment carried poor prognosis for ENKTCL,NT patients. ${ }^{12}$

CD2, CD3, CD7 and CD56 represents phenotypic markers for natural killer(NK) normal cells. ${ }^{2}$ In a study using tissue

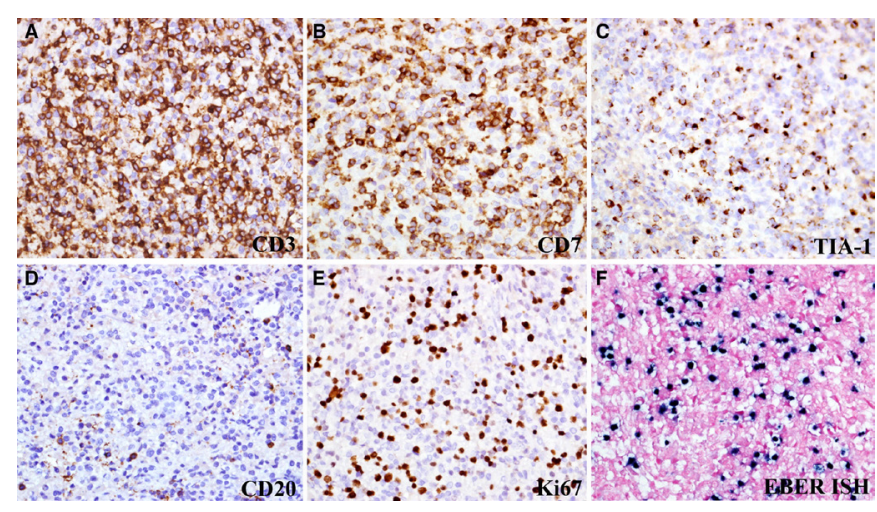

Figure 4 Immunohistochemistry and in situ hybridisation (ISH) staining pattern of extranodal NK/T cell lymphoma. The malignant lymphoid cells express: (A) CD3 (CD3×400). (B) CD7 (CD7×400). (C) TIA-1 (TIA-1×400). (D) B cell marker CD20 was negative $(C D 20 \times 400)$.

(E) Ki67 proliferative index was high, approximately 30\% (Ki67×400).

(F) Evidence of EBV-encoded small nuclear RNA-1 (EBER-1) (ISH x400), EBER, Epstein-Barr encoding region; EBV, Epstein-Barr virus. 
microarray, ENKTCL,NT were found positive for CD3, CD4, CD, CD7, CD45, CD30, CD56, TIA-1, granzyme B, Oct2, perforin and IRF4/MUM1, where TIA-1 was demonstrated in all of the 22 cases studied. ${ }^{18}$ In addition of positive EBER in situ hybridisation, TIA-1, CD2, CD3, CD5 and CD7 were positive in our patient, confirming the diagnosis of ENKTCL,NT. Although CD56 was negative, it did not rule out the diagnosis of ENKTCL, NT.

For ENKTCL, NT staging, Ann Arbour staging is generally used, however, some study suggested for tumour, node, metastasis (TNM) staging based on American Joint Committee of Cancer (AJCC) staging for nasopharyngeal carcinoma, or paranasal sinuses and nasal cavity cancers. ${ }^{19}$ In our patient, he was

\section{Patient's wife perspective}

'When my husband was first having the blocked nose, we thought it was simple influenza that usually would come and go by its own. However, subsequently it was associated with foul smelling and daily epistaxis. He also felt more weak. He was previously a healthy man and had a good job. He was retrenched around a month before he had the symptoms. He was previously working as a safety, health and environmental manager in an oil and gas company. During the economic recession, he lost his job and he tried to apply a new job to no avail. Hence, we blamed the stress that he was having due to his career downfall for his condition. However, he was getting weaker and his blocked nose made him breathing through his mouth, which made him always had dry mouth. Finally, we sought treatment at the hospital. When we found out about the cancer, we had expected the worst outcome and prepared for the treatment to come. We had three growing children. Luckily, he was not the only breadwinner in the family. He had underwent chemotherapy and stem cell transplant successfully. He was regaining his strength and was very well after the treatment. He went for jogging and fishing with his friends, and he was able to help with the household. Early year 2020, during the initial COVID-19 pandemic era, we were very careful with our contact and took care of our hygiene. Unfortunately, he died due to other causes other than previous cancer or its complications. However, his last days were fulfilled with doing things he used to loved. I am thankful for that.'

Learning points

- Extranodal NK/T cell lymphoma, nasal type (ENKTCL,NT) is a rare and aggressive type of non-Hodgkin's lymphoma, which constitutes only $3 \%-12 \%$ cases of non-Hodgkin's lymphoma, where higher percentage in Asia compared with Western countries.

- ENKTCL, NT presented with common nasal presentation such as nose blocked with hyposmia, nasal discharge and epistaxis and lead us to think of the more common diagnosis such as chronic rhinosinusitis, fungal rhinosinusitis, nasal tuberculosis and Wegener granulomatosis.

- Histopathology, immunochemical studies and in situ hybridisation Epstein-Barr encoding region are necessary to confirm the diagnosis of ENKTCL,NT.

- Gemcitabine, oxaliplatin and L-asparaginas regimen chemotherapy with additional intravenous gemcitabine and peripheral blood stem cell transplant showed a good outcome for our patient. diagnosed as stage IV ENKTCL, NT as he had bone marrow infiltration. Choices of treatment might be based on stages of the presenting ENKTCL, NT. Studies recommended chemotherapy with adjuvant radiotherapy as the gold standard treatment of ENKTCL, NT. Choices of chemotherapy may be varied. Recent study showed better outcome in patients receiving L-asparaginasebased regimens such as a combination of GELOX regimen, with overall 5 -year overall survival (OS) rate (OS) of $85 \%$, or a combination of dexamethasone, methotrexate, ifosfamide, L-asparaginase and etoposide (SMILE regimen), with 1-year OS of $55 \%$ or a combination of combined asparaginase, methotrexate and dexamethasone (AspaMetDex), showed 1-year OS of 61\%, as compared with a combination of cyclophosphamide, doxorubicin hydrochloride, vincristine sulfate, and prednisone-based regimen, with 5 -year OS of only $48 \%{ }^{20}$ There was also a study for concomitant chemoradiotherapy using a combination of dexamethasone, etoposide, ifosfamide and carboplatin regimen for localised ENKTL, with the 5 -year OS was $70 \% .^{21}$

In early-stage ENKTCL,NT, up to $85 \%$ of the patients may have complete remission with the current treatment based on chemotherapy regimen. However, advanced ENKTCL,NT (stage III/IV) had a very poor prognosis. ${ }^{22}{ }^{23}$ Despite of the challenge, a retrospective analysis showed favourable outcome for advanced ENKTCL,NT patients who received high-dose chemotherapy and peripheral blood stem cell transplant (PBSCT), with a 5 -year OS rate of $50 \% .{ }^{24}$ Further study on haematopoietic stem cells transplantation currently expanded for the future use of lymphoma treatment. ${ }^{25}$

Our patient was treated with GELOX regimen chemotherapy with additional intravenous gemcitabine and later with PBSCT. The result showed complete remission of the disease at an 18 months follow-up.

Acknowledgements The authors acknowledge with thanks the contribution of Farah Dayana Zahedi, Associate Professor of Rhinology, Specialist of Otorhinolaryngology; Aneeza Khairiyah Wan Hamizan, Associate Professor of Rhinology, Specialist of Otorhinolaryngology; and Ruhana Amirah binti Abdul Halim, Postgraduate student of Pathology Medicine, all three at Universiti Kebangsaan Malaysia for contributing information of the patient and interpreting the data in the case report.

Contributors The authors declare that no conflicts of interest exist in relation to the published work /describe potential conflicts of interest below*. ${ }^{*}$ ( ${ }^{\text {delete }}$ as applicable) Name and surname Signature Date (1) SSMR, 5 May 2021. (2) SH, 5 May 2021. (3) YPW, 5 May 2021 Permission from the head (heads) of the institution to submit the work for publication (not applicable to manuscripts submitted by independent research fellows): (1) SH, Head of Department, Department of Otorhinolarynology-Head and Neck Surgery, Faculty of Medicine, Universiti Kebangsaan Malaysia (UKM).

Funding This study was funded by Universiti Kebangsaan Malaysia 862406. Competing interests None declared.

Patient consent for publication Parental/guardian consent obtained. Provenance and peer review Not commissioned; externally peer reviewed.

Open access This is an open access article distributed in accordance with the Creative Commons Attribution Non Commercial (CC BY-NC 4.0) license, which permits others to distribute, remix, adapt, build upon this work non-commercially, and license their derivative works on different terms, provided the original work is properly cited and the use is non-commercial. See: http://creativecommons.org/ licenses/by-nc/4.0/.

\section{ORCID iDs}

Siti Sarah Mohd Ramli http://orcid.org/0000-0001-9566-3007

Salina Husain http://orcid.org/0000-0001-7683-2143

Yin Ping Wong http://orcid.org/0000-0003-4897-9927 


\section{REFERENCES}

1 Sellami N, Ghorbel L, Ben Salah H. Treatment and outcomes of Centrofacial NK/T cell lymphoma nasal type: a report of 8 cases and literature review. Annals of Clinical Pathology 2015:3:1043.

2 Suzuki R, Takeuchi K, Ohshima K, et al. Extranodal NK/T-cell lymphoma: diagnosis and treatment cues. Hematol Oncol 2008;26:66-72.

3 Tse E, Kwong Y-L. The diagnosis and management of NK/T-cell lymphomas. J Hematol Oncol 2017; 10:85.

4 Liu J, Song B, Fan T, et al. Pathological and clinical characteristics of 1,248 nonHodgkin's lymphomas from a regional cancer hospital in Shandong, China. Asian Pac J Cancer Prev 2011;12:3055-61.

5 Rüdiger T, Weisenburger DD, Anderson JR, et al. Peripheral T-cell lymphoma (excluding anaplastic large-cell lymphoma): results from the non-Hodgkin's lymphoma classification project. Ann Oncol 2002;13:140-9.

6 Vose J, Armitage J, Weisenburger D, et al. International peripheral T-cell and natural killer/T-cell lymphoma study: pathology findings and clinical outcomes. J Clin Oncol 2008;26:4124-30

7 William BM, Armitage JO. International analysis of the frequency and outcomes of NK/T-cell lymphomas. Best Pract Res Clin Haematol 2013;26:23-32.

8 Kwong Y-L. The diagnosis and management of extranodal NK/T-cell lymphoma, nasaltype and aggressive NK-cell leukemia. J Clin Exp Hematop 2011;51:21-8.

9 Stensland M, Klos J, Fluge Ø. Extranodal NK/T-cell lymphoma, nasal type, primarily involving ovary. Human Pathology: Case Reports 2017;9:58-60.

10 Kim GE, Koom WS, Yang W-I, et al. Clinical relevance of three subtypes of primary sinonasal lymphoma characterized by immunophenotypic analysis. Head Neck 2004;26:584-93.

11 Peh SC. Host ethnicity influences non-Hodgkin's lymphoma subtype frequency and Epstein-Barr virus association rate: the experience of a multi-ethnic patient population in Malaysia. Histopathology 2001;38:458-65.

12 Fei Q, Tian X-K, Wu J, et al. Prognostic significance of Epstein-Barr virus DNA in NK/Tcell lymphoma: a meta-analysis. Onco Targets Ther 2018;11:997-1004.

13 Chan J JE, Ralfakiaer E, Yh K. Agressive NK-cell leukemia. World Health organization (who) classification of tumors of hematopoietic and lymphoid tissues 2008:276-7.
14 Jaffe ES, Krenacs L, Raffeld M. Classification of cytotoxic T-cell and natural killer cell lymphomas. Semin Hematol 2003;40:175-84.

15 Miyake MM, Oliveira MVCde, Miyake MM, et al. Clinical and otorhinolaryngological aspects of extranodal NK/T cell lymphoma, nasal type. Braz J Otorhinolaryngol 2014;80:325-9.

16 Guedes JCR, Cunha KdeAPFda, Machado JRdaS, et al. Nasal-Type extranodal T-cell/ NK lymphoma in association with hemophagocytic syndrome. An Bras Dermatol 2018;93:422-5.

17 Liang R. Diagnosis and management of primary nasal lymphoma of T-cell or NK-cell origin. Clin Lymphoma 2000;1:33-7.

18 Pongpruttipan T, Kummalue T, Bedavanija A, et al. Aberrant antigenic expression in extranodal NK/T-cell lymphoma: a multi-parameter study from Thailand. Diagn Pathol 2011;6:79

19 Yan Z, Huang H-qiang, Wang X-xiao, et al. A TNM staging system for nasal NK/T-cell lymphoma. PLoS One 2015;10:e0130984.

20 Wang L, Wang Z-H, Chen X-Q, et al. First-Line combination of GELOX followed by radiation therapy for patients with stage IE/IIE ENKTL: an updated analysis with longterm follow-up. Oncol Lett 2015;10:1036-40.

21 Yamaguchi M, Tobinai K, Oguchi M, et al. Concurrent chemoradiotherapy for localized nasal natural killer/T-cell lymphoma: an updated analysis of the Japan clinical Oncology Group study JCOG0211. J Clin Oncol 2012;30:4044-6.

22 Harris NL, Jaffe ES, Diebold J, et al. World Health organization classification of neoplastic diseases of the hematopoietic and lymphoid tissues: report of the clinical Advisory Committee meeting-Airlie house, Virginia, November 1997. J Clin Oncol 1999; 17:3835-49.

23 Kim BS, Kim T-Y, Kim CW, et al. Therapeutic outcome of extranodal NK/T-cell lymphoma initially treated with chemotherapy--result of chemotherapy in NK/T-cell lymphoma. Acta Oncol 2003;42:779-83.

24 Kim HJ, Bang SM, Lee J, et al. High-Dose chemotherapy with autologous stem cell transplantation in extranodal NK/T-cell lymphoma: a retrospective comparison with non-transplantation cases. Bone Marrow Transplant 2006;37:819-24.

25 Verneris MR, Ito M, Baker J, et al. Engineering hematopoietic grafts: purified allogeneic hematopoietic stem cells plus expanded CD8+ NK-T cells in the treatment of lymphoma. Biol Blood Marrow Transplant 2001;7:532-42.

Copyright 2021 BMJ Publishing Group. All rights reserved. For permission to reuse any of this content visit https://www.bmj.com/company/products-services/rights-and-licensing/permissions/ BMJ Case Report Fellows may re-use this article for personal use and teaching without any further permission.

Become a Fellow of BMJ Case Reports today and you can:

- Submit as many cases as you like

Enjoy fast sympathetic peer review and rapid publication of accepted articles

- Access all the published articles

Re-use any of the published material for personal use and teaching without further permission

\section{Customer Service}

If you have any further queries about your subscription, please contact our customer services team on +44 (0) 2071111105 or via email at support@bmj.com.

Visit casereports.bmj.com for more articles like this and to become a Fellow 